\title{
EDITORIAL: TENDÊNCIAS, PERSPECTIVAS E DESAFIOS PARA A PROMOÇÃO DO ACESSO ABERTO À INFORMAÇÃO CIENTÍFICA DE ANGOLA
}

\author{
Eurico Wongo Gungula ${ }^{1}$ \\ https://orcid.org/0000-0002-5685-1328
}

O Seminário sobre a Criação, Gestão e Indexação de Revistas Científicas, realizado em Luanda, Angola, de 29 de Julho a 26 de Agosto de 2020 permitiu partilhar experiências com especialistas nacionais e internacionais sobre as consistências e inconsistências teóricas e práticas na compreensão geral das políticas internacionais sobre o Acesso Aberto à informação científica, bem como, sobre o Acesso Restrito a informação científica.

O supracitado seminário resultou de uma iniciativa liderada pelo Ministério do Ensino Superior, Ciência, Tecnologia e Inovação (MESCTI), em parceria com a Universidade Óscar Ribas (UÓR) e a Universidade Autónoma do Estado do México (UAEM), através da Rede de Revistas Científicas da América Latina e Caribe, Espanha e Portugal (Redalyc) e a AmeliCA Conhecimento Aberto, visando criar as condições práticas de melhoria da visibilidade das Revistas Científicas angolanas e, fundamentalmente, para a formação de pesquisadores angolanos.

Tendo em conta a sua ampla divulgação e pertinência, o seminário contou com a participação activa de mais de 312 profissionais dos 684 inscritos. Os participantes eram provenientes de 24 países, nomeadamente: Angola, Argentina, Bolívia, Brasil, Canadá, Chile, Colômbia, Costa Rica, Cuba, República Dominicana, Equador, França, Alemanha, Guiana, México, Peru, Portugal, Roménia, Federação Russa, Timor-Leste, Tunísia, Reino Unido, Estados Unidos da América, Venezuela e, mostraram um nível e índice médios de interesse na ordem dos $84 \%$ e $81,51 \%$ respectivamente.

Foram apresentadas significativas contribuições e questões que se resumem na necessidade de activação de políticas e estratégias de apoio à produção científica; de reconhecimento das causas da insuficiente visibilidade da produção científica de Angola no contexto nacional e internacional; de maior articulação entre o Projecto de Desenvolvimento de Ciência e Tecnologia (PDCT) e Instituto Nacional de Gestão de Bolsas de Estudos (INAGBE); de capacitação permanente dos professores e investigadores das distintas Instituições de Ensino Superior (IES) e das Instituições de Investigação e Desenvolvimento (II\&D); de criação de infraestruturas para promover a qualidade e quantidade das publicações científicas; de disseminação das políticas de publicação em revistas indexadas na Redalyc, SciELO, Web of Science e na Scopus.

Considerando que a produção e publicação de resultados científicos são, antes de mais, mecanismos credíveis de validação e consequente valorização dos resultados qualitativos, para que estes tenham uma maior probabilidade de serem citados internacionalmente, foram igualmente discutidas temáticas relacionadas com a internacionalização da ciência, compreensão das políticas editoriais das revistas de Acesso Restrito, de Acesso Aberto, por Subscrição, Predatórias, entre outras iniciativas.

Assim, considerando que a criação de uma rede de Revistas Científicas e a Promoção do Acesso Aberto à informação científica são relevantes para o desenvolvimento da investigação científica em Angola, o Ministério do Ensino Superior, Ciência, Tecnologia e Inovação formalizou, por Despacho N. ${ }^{\circ}$ 106/2021 de 30 Junho, a criação do Grupo Técnico composto por representantes das IES encarregues de dinamizar e implementar as acções inerentes à primeira fase

${ }^{1}$ Universidade Óscar Ribas, Angola. Email: euricowongowongo@gmail.com 
da iniciativa de criação da rede de Revisas Científicas e Promoção do Acesso Aberto à informação científica em território nacional.

Neste contexto, os desafios e perspectivas para a Promoção do Acesso Aberto à informação Científica em território nacional, contará com a orientação metodológica da Organização das Nações Unidas para a Educação, Ciência e Cultura (UNESCO), Redalyc, AmeliCA e, com o suporte das seguintes instituições: Universidade Óscar Ribas (UÓR-Luanda), Universidade Agostinho Neto (UAN-Luanda), Instituto Superior de Ciências da Educação (ISCED-Huíla), Instituto Superior Politécnico Sol Nascente (ISPSN-Huambo), Escola Superior Pedagógica (ESP-Bengo) e da Escola Superior Politécnica (ESP-Lunda Sul).

Assim, o Conselho Editorial da Revista SAPIENTIAE, visando a melhoria da qualidade dos artigos seleccionados para o volume 7-1, apresenta temas internacionais variados.

O primeiro refere-se a "Catálogo de tipologias documentais geradas pela Universidade Central "Marta Abreu" de Las Villas (1952-1983)", elaborado por Ailin González Jiménez e Asleni Díaz Jiménez, com o propósito de descrever a elaboração de um catálogo de tipologias documentais geradas pela Universidad Central "Marta Abreu" de Las Villas, no período compreendido entre 1952-1983. Para a identificação aplicou-se como metodologia o Modelo de Gestão de Documentos e Administração de Arquivos da Rede de Transparência e Acesso à Informação, criado em 2015, tendo como coordenadores principais, Beatriz Franco Espiño e Ricard Pérez Alcázar.

O segundo trata de "Estudos sociais acerca do desenvolvimento comunitário na América Latina e no Caribe: Capital de autoridade e citação", elaborado por Luis Ernesto Paz Enrique e Teresa del Pilar Muñoz Gutiérrez, com o objectivo de identificar o capital de autoridade e citação dentro do campo científico dos estudos sociais acerca do desenvolvimento comunitário na América Latina e no Caribe. O estudo foi classificado como descritivo, longitudinal - retrospectivo. Os métodos foram aplicados aos níveis teórico e empírico, fundamentalmente o método bibliométrico.

O terceiro é uma abordagem sobre "Avaliação das tele-aulas em tempo de COVID-19 pelos encarregados de educação de Luanda”, elaborado por Chocolate Brás, com a finalidade de reflectir sobre os resultados da avaliação das tele-aulas, realizada pelos encarregados de educação da província de Luanda durante o período de Estado de Emergência. O estudo concluiu que a produção das tele-aulas foi uma boa alternativa à suspensão das aulas presenciais apesar de $23,1 \%$ das crianças não as terem acompanhado, por distracção e falta de acompanhamento dos encarregados de educação, constantes cortes de energia eléctrica e da sua falta em algumas zonas, associado à falta de sinal de televisão, bem como de aparelho de televisão por parte de alguns agregados familiares.

O quarto é uma "Proposta de melhoria para a formação do pensamento refletivo a partir do processo de ensino-aprendizagem da Matemática na carreira de Engenharia", elaborado por María Teresa Ruiz García, Raquel Diéguez Batista e Raudel Torrecilla Díaz, com o objectivo de desenvolver um sistema de procedimentos didácticos para a formação do pensamento reflexivo a partir do ensino-aprendizagem da Matemática nas carreiras da Engenharia, baseado num modelo do processo de formação do pensamento reflexivo a partir desse processo formativo. $\mathrm{Na}$ elaboração do sistema de procedimentos didácticos foi utilizado o método estrutural sistémico, onde se estabelecem acções para orientar o processo de formação do pensamento reflexivo. Os resultados obtidos foram submetidos a Critérios de Especialistas que coincidem na adequação metodológica científica da pesquisa e a sua aplicação parcial corrobora o valor prático dos resultados.

$\mathrm{O}$ quinto refere-se à "Contracção dimensional sistemática: Uma proposta metodológica para o cálculo de equações e sistemas de equações lineares com incógnitas", elaborado por Francisco Lubota Bufeca Zau, com o objectivo de analisar a 
operacionalidade deste método de contracção dimensional sistemática no estudo de equações e sistemas lineares, a partir de técnicas homogéneas. Para o efeito, este artigo serve-se de uma pesquisa teórico-metodológica, de tipologia explicativa, com procedimentos técnicos bibliográficos e que utiliza o método indutivo-dedutivo.

O sexto é uma abordagem sobre "A educação em Ciência, Tecnologia e Sociedade para a formação investigativa do Engenheiro Civil" elaborado por Marlene Vilar de los Santos Finalé e Ramón Vidal Pla López, com o propósito de explicar um procedimento didáctico que contribua na formação investigativa dos estudantes a partir do processo de Ensino-Aprendizagem (PEA) da disciplina Problemas Sociais da Ciência e Tecnologia (PSCT), no curso de Engenharia Civil da Universidad Máximo Gómez Báez, Cuba.

O sétimo trata da "Responsabilidade social empresarial: Uma breve revisão teórica para o caso equatoriano", elaborado por Celio Froilán Andrade Cordero, com o objectivo de descrever a responsabilidade social na gestão empresarial equatoriana. Entre os factores contextuais que incidem na gestão do sector empresarial equatoriano, a incidência dos efeitos da pandemia da COVID-19 e a necessidade de incorporar a responsabilidade social como uma estratégia permanente de gestão empresarial para desenvolver vantagens competitivas que permitam propiciar um maior nível de vinculação com os grupos de interesse, sublinha-se a visão ética da co-responsabilidade empresa-sociedade.

O oitavo refere-se à "Cirurgia estética e motivações psicossociais: Estado da questão e perspectivas de investigação", elaborado por Luis Pérez García e Alicia Almanzar Curiel, com o objectivo de discutir aspectos relacionados com a modernidade tardia no México, as motivações psicossociais para a realização de cirurgia estética, experiências e um incremento constante verificado em cada ano, entre outros.

Como se pode observar, a significativa percentagem de investigadores internacionais cada vez mais comprometidos com o desenvolvimento da Revista SAPIENTIAE, fundamenta-se nas avaliações positivas da comunidade científica internacional sobre os seus processos editoriais.

É neste enquadramento que o Conselho Editorial da Revista SAPIENTIAE convida a comunidade científica nacional e internacional a revisar os artigos publicados, assim como a submeter novos artigos para a possível publicação em futuras edições. 